\title{
Assessment of Oral Hygiene Knowledge, Attitude, and Practices among Medical Students in a Medical College in the State of Telangana: A Cross-sectional Survey
}

\author{
G. Jagadish Reddy ${ }^{1}$ K. Suchithra ${ }^{2}$, A. Abhinav ${ }^{3}$, V. Ravikiran ${ }^{4}$ \\ Department of Periodontics, Kamineni Institute of Dental Sciences, Sreepuram, Narketpally, Telangana, India \\ Email for correspondence: drjagadishreddy@gmail.com
}

\begin{abstract}
Context: This is a knowledge, attitude, and practices model of analyzing the knowledge of oral hygiene aids, performance, and measures among medical students. Aim: The aim of the present study is to assess the knowledge, attitude, and practice of oral hygiene among medical students aged 17-35 years. Materials and Methods: 500 medical students of various grades were included in the study. Pre-tested structured closed-ended questionnaire was given to each student in their classrooms. All the questions regarding oral hygiene were filled by the students in 15-min duration. Results: $95.4 \%$ of subjects agree that oral health is important for general health. $69.4 \%$ of the participant's brush their teeth once daily, $28.4 \%$ of them brush twice daily, and $64.0 \%$ of the participants prefer combined type of motion. $49.0 \%$ individuals change their toothbrush once in $2-3$ months. $92.2 \%$ of subjects change their brushes in 2-3 months. Conclusion: The knowledge regarding oral hygiene w as satisfactory except knowledge about dental floss. Visiting a dentist is still not considered a preventive dental behavior.
\end{abstract}

Key words: Attitude, knowledge, medical students, oral hygiene, self-reported questionnaire

\section{INTRODUCTION}

Oral health is a vital component of the general health of an individual that influences on one's general quality of life and well-being. ${ }^{[1]}$ According to the World Oral Health report 2003, the prevalence of periodontitis is $86 \%$ in India. Oral health has been neglected for long in India. ${ }^{[2]}$ Enhanced oral health can be achieved with increased awareness and better practices. ${ }^{[1]}$

A knowledge, attitude, and practices (KAP) survey is a quantitative method (predefined questions formatted in standardized

\section{Quick Response Code Article Info:}

doi: 10.5866/2018.10.10007
Received: $18-12-2017$
Revised: $27-01-2018$
Accepted: $05-02-2018$
Available Online: $15-04-2018,2018$ (www.
nacd.in)@ NAD, 2017 - All rights reserved

questionnaires) that provides access to quantitative and qualitative information. KAP survey essentially records an "opinion" and is based on the "declarative" (i.e., statements). The survey reveals what was said, but there may be considerable gaps between what is said and what is done. ${ }^{[3]}$

KAP study tells us what people know about certain things, how they feel, and also how they behave. The knowledge possessed by a community refers to their understanding of any given topic oral hygiene in this case. Attitude is an acquired characteristic of an individual. People demonstrate a wide variety of attitudes toward dental care and dentists. ${ }^{[3]}$ These attitudes naturally reflect their own experiences, cultural perceptions, familial beliefs, and other life situations, and they strongly influence the health status of the oral cavity ${ }^{[1]}$ Practice refers to the ways in which they demonstrate their knowledge and attitude through their actions. ${ }^{[3]}$ 
Keeping a healthy oral profile requires joint efforts from the dentist as well as the patient himself. One of the most important factors that decide the dental health of a population is the outlook of its people toward their dentition. ${ }^{[4]}$ Students play a vital role in health promotion and preventive information dissemination among their family and their society, and therefore, their oral health attitude and practices conform to the expectations of the population. The booming young medical students are not exposed to health-care knowledge as dental professionals. ${ }^{[1]}$ Understanding the levels of KAP will enable a more efficient process of awareness creation as it will allow the program to be tailored more appropriately to the needs of the community. Hence, the present study was aimed to assess the KAP of oral hygiene among medical students aged $17-35$ years.

\section{METHODS}

\section{Ethical Clearance}

An observational, descriptive, cross-sectional survey study was conducted at Kamineni Institute of Medical Sciences, Nalgonda. This proposed study was reviewed by the Institutional Ethical Committee, and their clearance was obtained. A total of 500 students were selected using a convenience sampling technique. A informed consent was obtained from each patient.

\section{Study Sample and Sampling Technique}

A cross-sectional study using a 20-item structured was conducted to assess oral hygiene KAP in a sample of medical students $(n=500)$ [Graph 1].

All the semester students who were present on the day of survey were included in the study. Permission to conduct this study was obtained from the concerned authorities of the college, who in turn, through a circular, notified students about the intent of the study. Pilot study was conducted on 50 students for pre-testing of the questionnaire and to determine feasibility of the study.

\section{Questionnaire}

The study involved self-administration of pre-tested structured closed-ended questionnaire, to each student in their classrooms. Questionnaire consisted of 20 multiple choice questions to evaluate knowledge (5 questions) and attitude (5 questions); students received a full explanation on how to fill in the questionnaire. Students were asked to fill in the questionnaire without discussing with each other, and an average time of 15 min was taken to complete the procedure. It was made sure that none of the questions were left un-attempted. Anonymity of the respondents was assured. The students were then provided with health education regarding oral hygiene practices The study was completed within a period of 2 weeks.

\section{Statistical Analysis}

The data collected were compiled using Microsoft Office Excel and was subjected to statistical analysis using the statistical software package, Statistical Package for the Social Sciences version 19.0 for MS Windows, and $P$ $<0.05$ was considered statistically significant. Frequency distribution, number, and percentage were calculated. The descriptive statistics and statistical significance of any difference between the two genders were determined using Chi-square test.

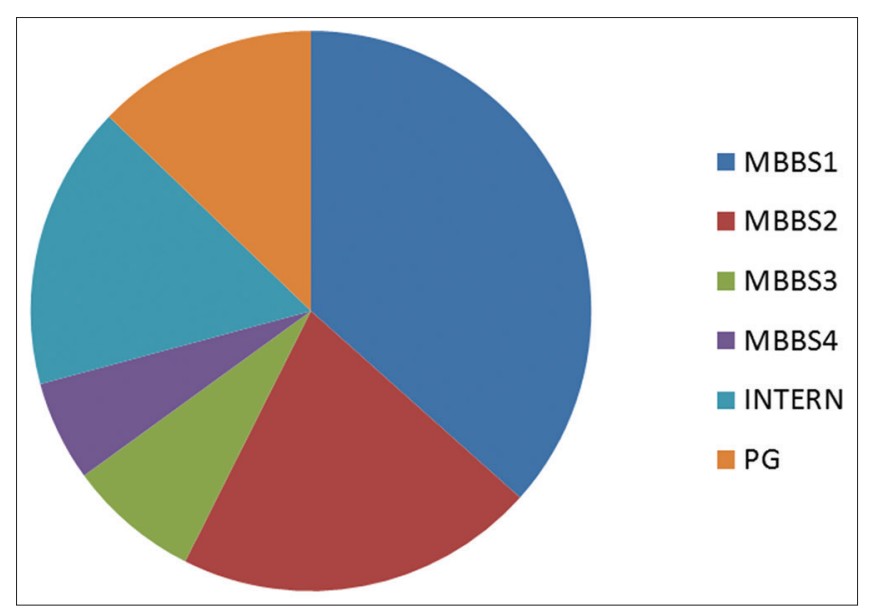

Graph 1: Total number of participants

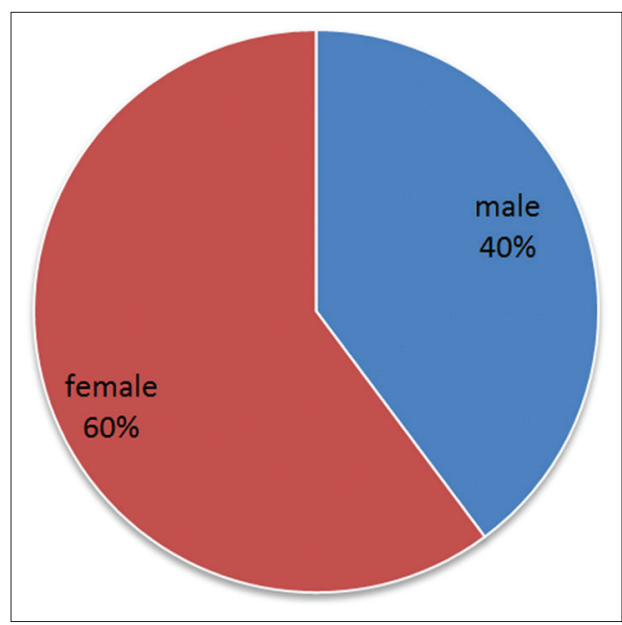

Graph 2: Gender distribution of participants 


\section{RESULTS}

The present study was carried out on 500 students. Among them, 40\% were males and 60\% were females [Graph 2].

Table 1 reveals that $96.6 \%$ of the participants agree that there are two sets of dentition in human beings, only $1 \%$ of the participants did not know about it, and $2.4 \%$ disagree with it. $91.8 \%$ of the participants had knowledge about the number of permanent teeth in an adult's mouth, whereas the remaining $8.2 \%$ of the participants did not have correct knowledge. $38.2 \%$ of the participants had knowledge about dental deposits, whereas $22.8 \%$ did not know about it and the rest of the participants, i.e., 39\% assume it to be the food particles or stains. The difference between males and females regarding knowledge of dental deposits was statistically significant $(P=0.004)$, and females had better knowledge regarding it. $72.6 \%$ of the participants had knowledge about interdental aids, whereas $27.4 \%$ of the students had no knowledge regarding it. The difference between males and females regarding knowledge about interdental aids was statistically significant $(P=0.003)$, and females had better knowledge regarding it. $75.4 \%$ of students knew that bleeding gums are related to our general health conditions, whereas $21.6 \%$ of the students disagree with that and $3 \%$ of them had no knowledge about it. The difference between males and females regarding the knowledge about bleeding gums corresponding to the general health condition was statistically significant $(P=0.038)$, and males had better knowledge regarding it.

Table 2 shows that most of the study population (95.4\%) think that oral health is important for overall health, whereas the remaining $4.6 \%$ do not think
Table 1: Comparison of gender related to knowledge of oral hygiene

$\begin{array}{ll}\text { Items } & \text { Male (\%) }\end{array}$

There are two sets of dentition in human beings,

baby teeth set, and permanent teeth set, and

permanent teeth set

Agree

Disagree

Do not know

$5(2.5)$

$3(1.5)$

How many permanent teeth are there in adults mouth

20

28

30

32

If there is a yellow or brownish yellow discoloration near tooth/gum, what is it

\section{Food particles}

Calculus/tartar

Stains

Do not know

Do you know there are some aids to clean the spaces

between teeth, which are named as interdental aids?

$$
\text { Yes }
$$

No

Is bleeding gums related to our general health condition

\begin{tabular}{lc} 
Agree & $162(81.4)$ \\
Disagree & $30(15.1)$ \\
Do not know & $7(3.5)$ \\
\hline
\end{tabular}

$* \mathrm{P}<0.05$ statistically significant

$\begin{array}{ccc}5(2.5) & 3(1.0) & 8(1.6) \\ 14(7.0) & 13(4.3) & 27(5.4) \\ 2(1.0) & 4(1.3) & 6(1.2) \\ 178(89.4) & 281(93.4) & 459(91.8)\end{array}$

$\begin{array}{lcc}28(14.1) & 38(12.6) & 66(13.2) \\ 59(29.6) & 132(43.9) & 191(38.2) \\ 66(33.2) & 63(20.9) & 129(25.8) \\ 46(23.1) & 68(22.6) & 114(22.8)\end{array}$

$\begin{array}{ccc}129(64.8) & 234(77.7) & 363(72.6) \\ 70(35.2) & 67(22.3) & 137(27.4)\end{array}$

$11.787-0.003^{*}$

$8.430 \quad 0.038^{*}$

$\begin{array}{cc}215(71.4) & 377(75.4) \\ 78(25.9) & 108(21.6) \\ 8(2.7) & 15(3.0)\end{array}$




\begin{tabular}{|c|c|c|c|c|c|}
\hline Items & Male (\%) & Female (\%) & Total $(\%)$ & Chi-square & P value \\
\hline $\begin{array}{l}\text { Do you think, oral health is important for overall } \\
\text { health? }\end{array}$ & & & & 1.661 & 0.436 \\
\hline Yes & $189(95.0)$ & $288(95.7)$ & $477(95.4)$ & & \\
\hline No & $10(5.0)$ & $13(4.3)$ & $23(4.6)$ & & \\
\hline How often should you visit the dentist? & & & & 3.374 & 0.497 \\
\hline Only in problem & $112(56.3)$ & $172(57.1)$ & $284(56.8)$ & & \\
\hline Once in 3 months & $19(9.5)$ & $24(8.0)$ & $43(8.6)$ & & \\
\hline Once in 6 months & $26(13.0)$ & $49(16.3)$ & $75(15.0)$ & & \\
\hline Never & $42(21.1)$ & $56(18.6)$ & $98(19.6)$ & & \\
\hline Reason for visiting the dentist? & & & & 7.577 & 0.181 \\
\hline Extraction & $2(1.0)$ & $8(2.7)$ & $10(2.0)$ & & \\
\hline As a routine visit & $53(26.6)$ & $95(31.6)$ & $148(29.6)$ & & \\
\hline Filling & $20(10.1)$ & $24(8.0)$ & $44(8.8)$ & & \\
\hline Scaling & $27(13.6)$ & $27(9.0)$ & $54(10.8)$ & & \\
\hline Replacement of teeth & $10(5.0)$ & $8(2.7)$ & $18(3.6)$ & & \\
\hline Others & $87(43.7)$ & $139(46.2)$ & $226(45.2)$ & & \\
\hline Reason for not having routine dental visit? & & & & 23.422 & $0.001^{*}$ \\
\hline Lack of time & $64(32.2)$ & $70(23.3)$ & $134(26.8)$ & & \\
\hline Lack of access & $12(6.0)$ & $4(1.3)$ & $16(3.2)$ & & \\
\hline Expensive & $8(4.0)$ & $20(6.6)$ & $28(5.6)$ & & \\
\hline Lack of knowledge and motivation & $4(2.0)$ & $25(8.3)$ & $29(5.8)$ & & \\
\hline I never had a problem & $94(47.2)$ & $163(54.2)$ & $257(51.4)$ & & \\
\hline Others & $17(8.5)$ & $19(6.3)$ & $36(7.2)$ & & \\
\hline Which one do you prefer to clean your teeth? & & & & 8.241 & 0.083 \\
\hline Toothbrush and toothpaste & $191(96.0)$ & $293(97.3)$ & $484(96.8)$ & & \\
\hline Toothbrush and powder & $3(1.5)$ & $7(2.3)$ & $10(2.0)$ & & \\
\hline Others & $5(2.5)$ & $1(0.3)$ & $6(1.2)$ & & \\
\hline
\end{tabular}

$* \mathrm{P}<0.05$ statistically significant

that it is important. $56.8 \%$ of the participants visit the dentist only in problem, whereas $19.6 \%$ of them never visited the dentist. Of the study population, $10.8 \%$ prefer scaling as the reason for visiting the dentist, $29.6 \%$ said as a routine visit, and $45.2 \%$ said for other reasons such as bleeding gums and orthodontic treatment... According to $51.4 \%$ of the study population, they never had a problem, it is the main reason for not having routine dental visits, $5.6 \%$ of the participants think that dental treatment is expensive, and $26.8 \%$ of the students could not visit the dentist due to lack of time. The difference between males and females regarding the reason for not having routine dental visits is statistically significant $(P<0.05) .96 .8 \%$ of the participants had a good attitude of using toothbrush and toothpaste to clean the teeth, and $2 \%$ of the individuals prefer toothbrush and toothpowder.

Table 3 reveals that $69.4 \%$ of the participants brush their teeth once daily, $28.4 \%$ of them brush twice daily, and $1.6 \%$ of the individuals brush occasionally. The difference between males and females regarding the frequency of toothbrushing was statistically significant $(P=0.032) .64 .0 \%$ of the participants prefer the combined type of motion; $7.6 \%$ of the individuals use vertical motion; $9.4 \%$ of the individuals prefer horizontal motion; and $19.0 \%$ of the individuals prefer circular motion while brushing. $48.8 \%$ of the population had a practice of using medium bristled toothbrush; $37.2 \%$ used softbristled toothbrush, whereas only $4.4 \%$ used hardbristled toothbrush and $9.6 \%$ of the individuals never 


\section{Table 3: Continued}

\begin{tabular}{|c|c|c|c|c|c|}
\hline Items & Male (\%) & Female (\%) & Total $(\%)$ & Chi-square & P value \\
\hline How often do you brush your teeth? & & & & 8.821 & $0.032^{*}$ \\
\hline Once a day & $133(66.8)$ & $214(71.1)$ & $347(69.4)$ & & \\
\hline Twice a day & $57(28.6)$ & $85(28.2)$ & $142(28.4)$ & & \\
\hline More than twice a day & $2(1.0)$ & $1(0.3)$ & $3(0.6)$ & & \\
\hline Occasionally & $7(3.5)$ & $1(0.3)$ & $8(1.6)$ & & \\
\hline What type of motion do you use while brushing? & & & & 1.239 & 0.744 \\
\hline Vertical & $17(8.5)$ & $21(7.0)$ & $38(7.6)$ & & \\
\hline Horizontal & $17(8.5)$ & $30(10.0)$ & $47(9.4)$ & & \\
\hline Combined & $124(62.3)$ & $196(65.1)$ & $320(64.0)$ & & \\
\hline Circular & $41(20.6)$ & $54(17.9)$ & $95(19.0)$ & & \\
\hline What type of brush do you use? & & & & 4.520 & 0.210 \\
\hline Hard & $11(5.5)$ & $11(3.7)$ & $22(4.4)$ & & \\
\hline Medium & $106(53.3)$ & $138(45.8)$ & $244(48.8)$ & & \\
\hline Soft & $65(32.7)$ & $121(40.2)$ & $186(37.2)$ & & \\
\hline Never noticed & $17(8.5)$ & $31(10.3)$ & $48(9.6)$ & & \\
\hline How often you change your toothbrush? & & & & 14.368 & $0.002^{*}$ \\
\hline Monthly & $63(31.7)$ & $91(30.2)$ & $154(30.8)$ & & \\
\hline $2-3$ months & $105(52.8)$ & $140(46.5)$ & $245(49.0)$ & & \\
\hline $4-5$ months & $14(7.0)$ & $55(18.3)$ & $69(13.8)$ & & \\
\hline When bristles flare & $17(8.5)$ & $15(5.0)$ & $32(6.4)$ & & \\
\hline Do you clean your tongue? & & & & 2.328 & 0.127 \\
\hline Yes & $179(89.9)$ & $282(93.7)$ & $461(92.2)$ & & \\
\hline No & $20(10.1)$ & $19(6.3)$ & $39(7.8)$ & & \\
\hline Do you rinse your mouth after eating? & & & & 0.953 & 0.329 \\
\hline Yes & $165(82.9)$ & $239(79.4)$ & $404(80.8)$ & & \\
\hline No & $34(17.1)$ & $62(20.6)$ & $96(19.2)$ & & \\
\hline Do you use a mouthwash? & & & & 6.101 & $0.047^{*}$ \\
\hline Yes & $78(39.2)$ & $91(30.2)$ & $169(33.8)$ & & \\
\hline No & $121(60.8)$ & $210(69.8)$ & $331(66.2)$ & & \\
\hline Have you ever noticed smell from your mouth? & & & & 3.991 & 0.262 \\
\hline Yes & $90(45.2)$ & $106(35.2)$ & $196(39.2)$ & & \\
\hline No & $109(54.8)$ & $195(64.8)$ & $304(60.8)$ & & \\
\hline $\begin{array}{l}\text { Apart from brushing, what other methods do you } \\
\text { use to clean your teeth? }\end{array}$ & & & & 4.235 & 0.237 \\
\hline Dental floss & $25(12.6)$ & $40(13.3)$ & $65(13.0)$ & & \\
\hline Interdental brushes & $10(5.0)$ & $16(5.3)$ & $26(5.2)$ & & \\
\hline Tooth pricks & $74(37.2)$ & $86(28.6)$ & $160(32.0)$ & & \\
\hline None & $90(45.2)$ & $159(52.8)$ & $249(49.8)$ & & \\
\hline Have you ever noticed bleeding in your gums? & & & & 5.710 & 0.127 \\
\hline Yes & $56(28.1)$ & $82(27.2)$ & $138(27.6)$ & & \\
\hline No & $143(71.9)$ & $219(72.75)$ & $362(72.4)$ & & \\
\hline If yes, what method you prefer to control bleeding & & & & 4.085 & 0.395 \\
\hline
\end{tabular}




\begin{tabular}{|c|c|c|c|c|c|}
\hline Items & Male (\%) & Female (\%) & Total (\%) & Chi-square & $P$ value \\
\hline Visit a medical practitioner & $9(14.5)$ & $15(16.9)$ & $24(15.9)$ & & \\
\hline Visit a dentist & $17(27.4)$ & $31(34.8)$ & $48(31.8)$ & & \\
\hline Use some home remedies & $19(30.6)$ & $26(29.2)$ & $45(29.8)$ & & \\
\hline Wait for bleeding to reoccur & $13(21.0)$ & $16(18.0)$ & $29(19.2)$ & & \\
\hline Others & $4(6.5)$ & $1(1.1)$ & $5(3.3)$ & & \\
\hline
\end{tabular}

$* \mathrm{P}<0.05$ statistically significant

noticed the particular type of toothbrush. Majority $49.0 \%$ of individuals change their toothbrush once in $2-3$ months, whereas $30.8 \%$ change it monthly and $6.4 \%$ change when it is spoilt.

The difference between males and females, regarding the practice of changing toothbrush, was statistically significant $(P=0.002) .92 .2 \%$ of the participants clean their tongue and prefer to use a tongue cleaner for this. 80.8\% of the people had a good practice of rinsing their mouth after eating. Only $33.8 \%$ of the individuals had a practice of using mouthwash; $66.2 \%$ of the participants do not use mouthwash, and the difference between males and females, regarding the use of mouthwash, was statistically significant $(P=0.047) .60 .8 \%$ of the individuals never noticed smell from their mouth. In addition to toothbrush, $32.0 \%$ used tooth pricks, only $13.0 \%$ had a good practice of using dental floss, and $5.2 \%$ used interdental brushes. Only $27.6 \%$ of the participants noticed bleeding in their gums; of them, $31.8 \%$ had a good practice of visiting the dentist and $28.8 \%$ of the participants waited for bleeding to reoccur. The results of the study have pointed out that educational level was one of the important factors that governed the knowledge, attitude, and oral hygiene practices of the people.

\section{DISCUSSION}

It has been observed that oral hygiene has mostly remained as an ignored and unrealized major social problem. ${ }^{[2]}$

According to the consumer usage and attitudes study done in 2010, the most shocking observation is that nearly half of the Indian population does not use a toothbrush and only 51\% brushed their teeth using a toothbrush and toothpaste. ${ }^{[2]}$

Over the past 20 years, a significant amount of emphasis has been made on prevention of diseases rather than the treatment aspect. Healthy teeth can last us a lifetime with the proper preventive dental care. Preventive oral health knowledge, attitude, and its practice are the important ways of keeping our teeth healthy. ${ }^{[2]}$ Hence, in the present study, attempts were made to evaluate preventive oral health knowledge, practice, and attitude of the population of medical students in a private medical college.

In the present study, the knowledge regarding oral hygiene was satisfactory except knowledge about dental floss, whereas poor knowledge on the perception of oral health was reported among engineering students of Tiruchengode. ${ }^{[5]}$

In the present study, only $28.4 \%$ [Table 3] of the medical students reported of brushing their teeth twice daily and it was in contrary with the results of Peltzer and Pengpid who reported it to be $67.2 \%$ in university students of 26 low-, middle-, and highincome countries. ${ }^{[6]}$ On the contrary, Rimondini et al. ${ }^{[7]}$ described a much higher percentage $(92.1 \%)$ in Italian University students, whereas Prasad et al. ${ }^{[5]}$ and Gasgoos et al.$^{[8]}$ reported small percentage $30.7 \%$ and $15.4 \%$, respectively. The present observation may be due to the occupancy of the students in their curricular activities and ignorant attitude toward oral hygiene, considering it as less important.

In the present study, males brush their teeth more frequently than females [Table 3] which were statistically significant $(P=0.05)$, and it was contrary with the result of El-Qaderi and Taani, ${ }^{[9]}$ Gasgoos et al. ${ }^{[8]}$ and Prasad et al. ${ }^{[5]}$ where females brush their teeth more frequently. This difference can attribute to a higher regarding personal hygiene and health care among males.

Hamilton and Coulby found that a high percentage (44\%) studied in North Eastern Ontario used dental floss; in contrast, this current study reported only $13 \%$ [Table 3] of students used dental floss. ${ }^{[10]}$ Reason for this may be the significant resource allocation to health education programs that are carried out in Canada. This emphasizes the urgent need for educating and motivating the public to use this efficient method for oral health 
care. Majority of the studied population showed that they clean their tongue either with toothbrush or tongue cleaner. Furthermore, 80.8\% [Table 3] of the sample population rinses their mouth after eating food. This very basic method of maintaining oral hygiene is a clear indication of good awareness.

It is noteworthy that $64 \%$ [Table 3] of the respondents brushed their teeth using combined motion, which is in contrary to the horizontal motion causing jeopardize of the tooth structure. This finding is in contrary with that of the study done by Zhu et al. ${ }^{[11]}$ where $60 \%$ of the sample used horizontal motion. Only $37.2 \%$ [Table 3] of the subjects use soft brush, which is more than that observed among Zhu et al.'s subjects where $27 \%$ of the sample use the same. [11] $49 \%$ change their toothbrush once in 3 months [Table 3], and surprisingly 6.4\% [Table 3] change their brush only when it is useless. 33.8\% [Table 3] of subjects used a mouthwash. Interestingly enough, they used it to treat malodor. Furthermore, 39.7\% reported halitosis. The present study is in contrast with that of an epidemiologic survey of the general population of Japan where $24 \%$ of the individuals examined complained about bad breath.

$27.6 \%$ [Table 3] of the total subjects reported bleeding gums. The present study is in contrary with the studies of Gilbert and Nuttal and Buhlin et al. who showed that selfreported bleeding gums were high in percentage. ${ }^{[12,13]}$ The present study is in agreement with the studies of Tervonen and Knuttila and Kallio et al. who showed that most of the patients did not notice bleeding from gums. ${ }^{[14,15]}$

Visiting a dentist is still not considered a preventive dental behavior, and at present, it only depends on the treatment needs. ${ }^{[16]}$ The present study shows that around 75\% [Table 2] of the patients visited the dentist only in problem and only $10 \%$ [Table 2] of the population visited the dentist on regular basis after every 6 months. These results are similar to the study done by Jain et al., where $54 \%$ of the subjects visited the dentists when there is a problem. ${ }^{[2]}$ These results are also equivocal with the study conducted by Maryln et al. in which $67.9 \%$ of the study population reported having had a dental checkup at least once a year in the past 5 years. ${ }^{[17]}$

\section{Limitations}

Student's self-reporting of behaviors may have resulted in over-reporting of proper hygiene practices. Determination of causality is difficult using this cross-sectional study design.

\section{CONCLUSION}

The present study presented a comprehensive overview of oral health-related KAP among medical students in a private medical college in Nalgonda. The awareness about the oral health of the studied subjects stands acceptable. Knowledge about dental floss and frequency of visiting the dentist and brushing frequency was inadequate. More concentration needs to be undertaken regarding oral health care in terms of health education programs.

We, as dentists, will have to keep reinforcing the importance of correcting all aspects related to brushing and flossing along with the importance of regular checkups.

\section{ACKNOWLEDGMENT}

The authors wish to thank all the medical students participated, for their kind cooperation throughout the survey.

\section{REFERENCES}

1. Kakkad DN, Murali R, Krishna M, Yadav S, Yalamalli M, Kumar AV. Assessment of oral hygiene knowledge, attitude, and practices among engineering students in north Bangalore: A cross-sectional survey. Int J Sci Stud 2015;3:84-9.

2. Jain N, Mitra D, Ashok KP, Dundappa J, Soni S, Ahmed S. Oral hygiene-awareness and practice among patients attending OPD at Vyas dental college and hospital, Jodhpur. J Indian Soc Periodontol 2012;16:524-8.

3. Kamran A, Bakhteyar K, Heydari H, Lotfi A, Heydari Z Survey of oral hygiene behaviors, knowledge and attitude among school children: A cross-sectional study from Iran. Int J Health Sci 2014;2:83-95.

4. Kapoor S, Gill S, Singh A, Kaur I, Kapoor P. Oral hygiene awareness and practice amongst patients visiting the department of periodontology at a dental college and hospital in North India. Indian J Dent 2014;5:64-8.

5. Prasad AK, Shankar S. Oral health KAP of first year engineering students of KSR College of technology, Thiruchengode, the future rulers. J Indian Assoc Public Health Dent 2010;16:143-7.

6. Peltzer K, Pengpid S. Oral health behaviour and social and health factors in university students from 26 low, middle and high income countries. Int J Environ Res Public Health 2014; 11:12247-60.

7. Rimondini L, Zolfanelli B, Bernardi F, Bez C. Self-preventive oral behavior in an Italian university student population. J Clin Periodontol 2001;28:207-11.

8. Gasgoos SS, Jazrawi KH, Ajrab MG. Dental health knowledge, attitude and behavior among first year university students, Mosul. Al-Rafidain Dent J 2007;7:138-52.

9. El-Qaderi SS, Taani DQ. Oral health knowledge and dental 
health practices among school children in Jerash district/ Jordan. Int J Dent Hyg 2004;2:78-85.

10. Hamilton ME, Coulby WM. Oral health knowledge and habits of senior elementary school students. J Public Health Dent 1991;51:212-9.

11. Zhu L, Petersen PE, Wang HY, Bian JY, Zhang BX. Ora health knowledge, attitudes and behaviour of adults in China. Int Dent J 2005;55:231-41.

12. Gilbert AD, Nuttal NM. Self-reporting of periodontal health status. Br Dent J 1999;186:241-4.

13. Buhlin K, Gustaffon A, Anderson K, Hakansson K, Klinge B Validity and limitations of self-reported periodontal health. Community Dent Oral Epidemiol 2002;30:431-7.
14. Tervonen T, Knuttila M. Awareness of dental disorders and discrepancy between objective and subjective dental treatment needs. Community Dent Oral Epidemiol 1988;34:345-8

15. Kallio P, Nordblad A, Croucher R, Ainamo J. Self-reported gingivitis and bleeding gums among adolescents in Helsinki. Community Dent Oral Epidemiol 1994;22:277-82.

16. Gundala R, Chava VK. Effect of lifestyle, education and socioeconomic status on periodontal health. Contemp Clin Dent 2010;1:23-6.

17. Survey of Family Tooth Brushing Practices. Bureau of dental health education. Bureau of research and statistics. J Am Dent Assoc 1966;72:1489-91. 